\title{
STUDIES ON HYPERVENTILATION. II. ELECTROCARDIOGRAPHIC CHANGES IN NORMAL MAN DURING VOLUNTARY HYPERVENTILATION 1,2
}

\author{
By B. CHR. CHRISTENSEN \\ (From the Medical Out-Patient Department of the Kommunehospital, Copenhagen, Denmark. \\ Chief: Physician-in-Chief Poul Schulzer)
}

(Received for publication August 1, 1946)

Any normal human being will present certain cardiac symptoms, besides the well-known tetany signs, during voluntary hyperventilation, which removes carbon dioxide. Thus a feeling of precordial oppression, in some cases increasing to proper precordial pains with eradiation to the left arm, and often accompanied by an unaccountable sensation of fear, will generally develop after 1 or 2 minutes of hyperventilation. Continued hyperventilation for another 2 or 3 minutes will, in many cases, bring about a pronounced feeling of air hunger.

The above signs and symptoms are suggestive of the presence of a transitory coronary insufficiency. It therefore seems reasonable to find out whether signs of coronary insufficiency can be demonstrated electrocardiographically during voluntary hyperventilation.

A number of reports have been published on electrocardiographic examinations during hyperventilation. Kronenberger and Ruffin state that they have observed flattening of the $T$ waves in one or more leads in 8 cases during attacks of hyperventilation tetany, whereas electrocardiograms registered between these attacks presented perfectly normal conditions. These writers hold that the changes occurring during the hyperventilation are caused by an increased vagal tonus. McCance (2) has observed similar changes during attacks of hyperventilation in 2 patients, but he is unable to give an explanation of the occurrence of these changes. Lami (3), who has experimented with 25 normal subjects, has also found a flattening of the $\mathrm{T}$ waves together with a decrease in the heights of the $R$ waves in one or more leads during voluntary hyperventilation. This writer is of the opinion that the changes are due to a change of position of the heart brought about by a local

\footnotetext{
1 Financial support for these studies has been granted from Kong Christian den Tiendes Fond.

2 Read, in a somewhat modified form, before the Danish Society of Internal Medicine on April 26, 1946.
}

tetany in the diaphragm. Barker and collaborators (4) have observed the same changes in 4 normal subjects during voluntary hyperventilation, and have, besides, managed to bring about such changes by administration of large amounts of sodium bicarbonate. These writers are likewise unable to give an explanation to the occurrence of the changes. Barach and Steiner (5) have regarded the problem from the opposite side, in so far as they have tried to find out, whether it should be possible to change a pathological electrocardiogram by letting patients suffering from coronary sclerosis breathe in air containing carbon dioxide. The result of their experiments was that in 20 out of 26 cases the $T$ waves became slightly higher in one or more leads during respiration of air containing carbon dioxide; and they suppose that the changes are due to the coronary vessels being dilated during the acidosis which is brought about by the carbon dioxide.

The report here presented is the outcome of 40 experiments carried out on 4 normal persons between the ages of 15 and 42 . In some of the experiments, only the 3 usual extremital leads have been registered, while in others also the precordial lead $4 \mathrm{R}$ has been applied. All deflections were registered synchronously, except in the case of the first person. The rate was calculated on the basis of the time elapsing between 8 successive $R$ waves. The electrocardiograph was for all registrations adjusted in such a manner that a difference of tension of 1 millivolt brought about a deflection of $10 \mathrm{~mm}$. The measurement of the heights of the individual waves was carried out according to Kaj. H. Larsen's method (6), in which the straight line tangent to the lower border of the curve on the segment between the end of the $P$ wave and the beginning of the initial complex is used as the iso-electric level. This line does not always run a horizontal course, but may be either slightly ascending or descending. In such cases the straight line tangent to the curve at the beginning of the 
initial complex is used as the iso-electric level. The latter must be the straight line tangent to the lower border of the curve between the end of the $T$ wave, or sometimes the $U$ wave, and the beginning of the $P$ wave, as the electrocardiographic curve between the end of the $P$ wave and the beginning of the initial complex will sometimes run a few tenths of a millimeter below the T-P segment. The stated heights of the individual waves have, like the indicated times, been calculated as the average of the respective values of 5 successive complexes.

\section{METHODS}

The experiments were carried out in the morning and were commenced after the subjects, who were fasting, had lain in rest for 1 hour in the laboratory. After this period of rest, 2 electrocardiograms were registered at intervals of 5 minutes in order to make sure that the electrocardiogram presented no spontaneous changes of any note. Next the hyperventilation was started in atmospheric air. During the hyperventilation the subject tried to increase both depth and rate of respiration as much as possible. Three to 5 electrocardiograms were registered within this part of the experiment, which lasted from 3 to 8 minutes. In some of the experiments the spontaneous decline of the electrocardiographic changes was studied next by registration of from 5 to 10 electrocardiograms within up to half an hour. In the remaining experiments the hyperventilation was continued, with pure oxygen being given in some cases, and a mixture of 5 per cent carbon dioxide, 20 per cent oxygen, and 75 per cent nitrogen in others. Finally some experiments were made in which $2 \mathrm{mgm}$. nitroglycerin were given immediately before the commencement of the hyperventilation.

\section{RESULTS}

When double experiments were carried out, the changes always proved to be fairly similar in both sets of electrocardiograms; and great accordance was likewise demonstrated between the changes observed for the different subjects.

Some of the electrocardiograms are rather unsatisfactory from a technical point of view, because the registrations had to be made during strong hyperventilation, and in a few cases, at a point of time at which the subject presented a manifest tetany.

Electrocardiographic changes during voluntary hyperventilation. Voluntary hyperventilation brings about pronounced and characteristic changes in the electrocardiogram, as will be demonstrated.

Figure 1 illustrates the action of the heart of a girl aged 17. The first set, which was registered before the hyperventilation was commenced, shows quite normal conditions. The second set, which was registered after 5 minutes of hyperventilation
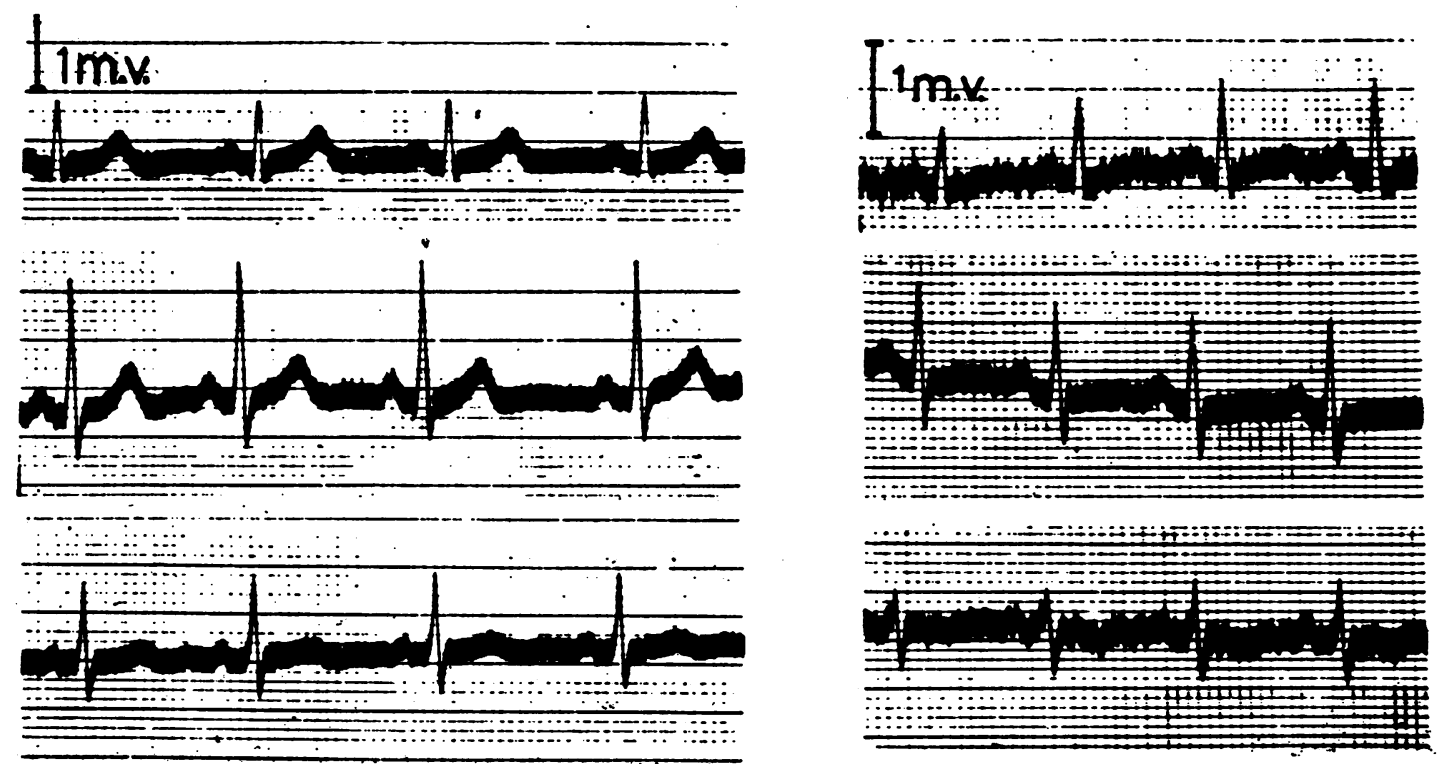

Fig. 1. Electrocardiograms from Subject No. 1

The first EKG was registered during normal respiration; the second EKG, after 5 minutes of hyperventilation in atmospheric air. 
in atmospheric air, shows the following changes: The rate has increased from 85 to $110 . T_{1}$ has decreased from $2 \frac{1}{2} \mathrm{~mm}$. to $1 \mathrm{~mm}$.; $\mathrm{T}_{2}$, from $3 \frac{1}{2}$ to $0 \mathrm{~mm}$. ; and $\mathrm{T}_{8}$, from +1 to $-1 \mathrm{~mm}$. At the same time $R_{2-3}$ have become somewhat lower.

The second person experimented on was a girl aged 15 (Figure 2). The first set was registered before the beginning of the experiment; the second set, after hyperventilation for 2 minutes; and the third set, after 5 minutes of hyperventilation. The hyperventilation is here seen to have changed, particularly the S-T segment and the $T$ waves in the second and third leads. The $\mathrm{S}-\mathrm{T}$ segment has become depressed 1 to $11 / 2 \mathrm{~mm}$., and at the same time $T_{2-3}$ have become iso-electric or nega- tive. The sizes of the individual changes appear from Table I.

The next experiment to be mentioned was made on a woman aged 42 . Figure 3 shows first a set of normal electrocardiograms, which were registered immediately before the beginning of the experiment. The next 5 electrocardiograms were registered after hyperventilation for $2,3,4,6$, and 7 minutes respectively. The precordial electrode failed to act at the registration of the 2 last electrocardiograms. Very massive changes, particularly of the $\mathrm{S}-\mathrm{T}$ segment and the $\mathrm{T}$ waves, are seen here in all 4 leads. The sizes of the individual changes appear from Table II.

The fourth person experimented on was a wo-

TABLE I

The electrocardiographic changes presented by subject no. 2 during voluntary hyperventilation Time indicated in seconds. Height of waves in $\mathrm{mm}$.

\begin{tabular}{|c|c|c|c|c|c|c|c|c|c|c|c|c|c|c|c|}
\hline Point of time & Rate & P-Q & Q-T & $\mathbf{P}_{\mathbf{1}}$ & $\mathbf{P}_{\mathbf{2}}$ & $\mathbf{P}_{\mathbf{3}}$ & $\mathbf{R}_{\mathbf{1}}$ & $\mathbf{R}_{\mathbf{2}}$ & $\mathbf{R}_{\mathbf{z}}$ & $S-T_{1}$ & $S-T_{2}$ & $S-T_{2}$ & $\mathrm{~T}_{1}$ & $T_{2}$ & $T_{2}$ \\
\hline $\begin{array}{l}\text { Before hyperventilation } \\
\text { a. } 2 \mathrm{~min} \text {. of hyperventilation } \\
\text { a. } 5 \mathrm{~min} \text {. of hyperventilation }\end{array}$ & $\begin{array}{r}62 \\
120 \\
120\end{array}$ & $\begin{array}{l}0.16 \\
0.16 \\
0.14\end{array}$ & $\begin{array}{l}0.34 \\
0.26 \\
0.26\end{array}$ & $\begin{array}{l}1 \\
1 \\
1\end{array}$ & $\begin{array}{l}2 \\
2 \frac{1}{4} \\
2 \frac{1}{4}\end{array}$ & $\begin{array}{l}1 \\
1 \frac{1}{4} \\
1 \frac{1}{6}\end{array}$ & $\begin{array}{l}5 \\
3 \\
4\end{array}$ & $\begin{array}{l}17 \\
18 \\
16\end{array}$ & $\begin{array}{l}14 \\
16 \\
13\end{array}$ & $\begin{array}{l}0 \\
0 \\
0\end{array}$ & $\begin{array}{l}0 \\
-1 \\
-1 \frac{1}{2}\end{array}$ & $\begin{aligned} & 0 \\
- & 1 \frac{1}{2} \\
- & 1 \frac{1}{2}\end{aligned}$ & $\begin{array}{l}1 \\
0 \\
0\end{array}$ & 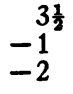 & $\begin{aligned} & 2 \frac{1}{2} \\
- & 1 \\
- & 1 \frac{1}{2}\end{aligned}$ \\
\hline
\end{tabular}
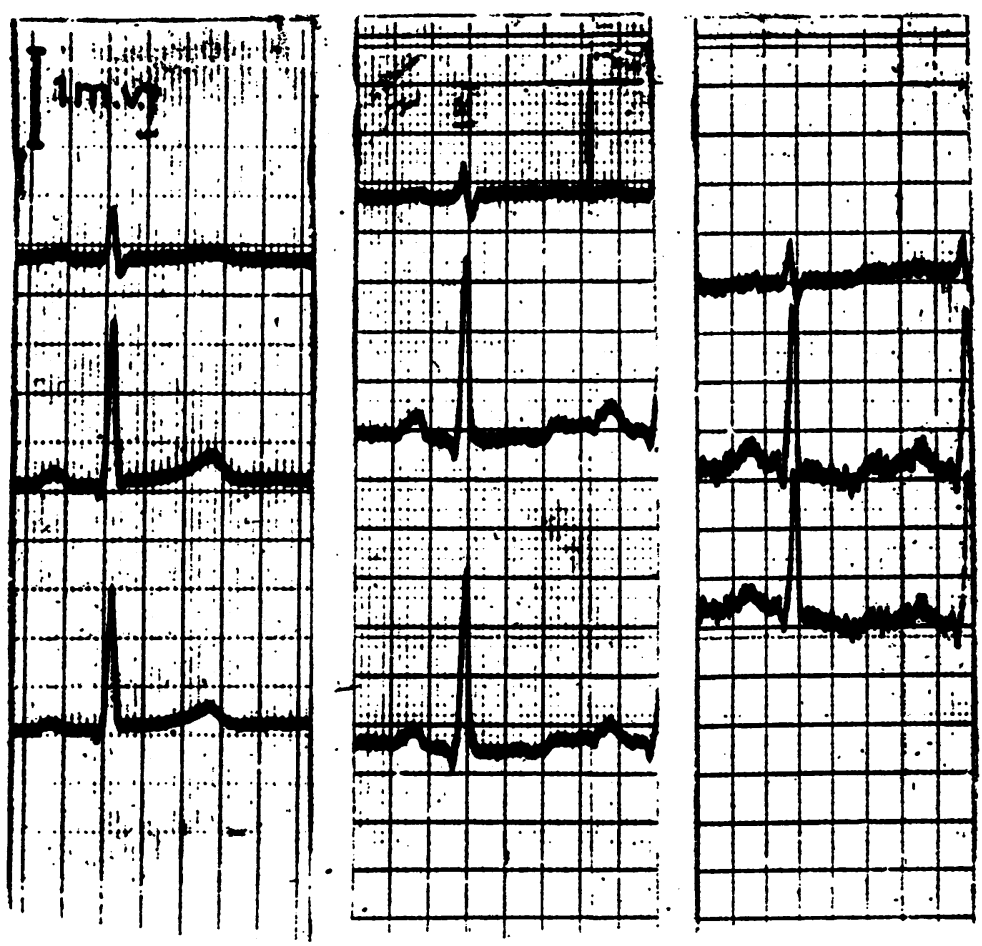

Fig. 2. Electrocardograms from Sưbject No. 2

The first EKG was registered during normal respiration; the second and third sets, after hyperventilation in atmospheric air for 2 and 5 minutes respectively. 


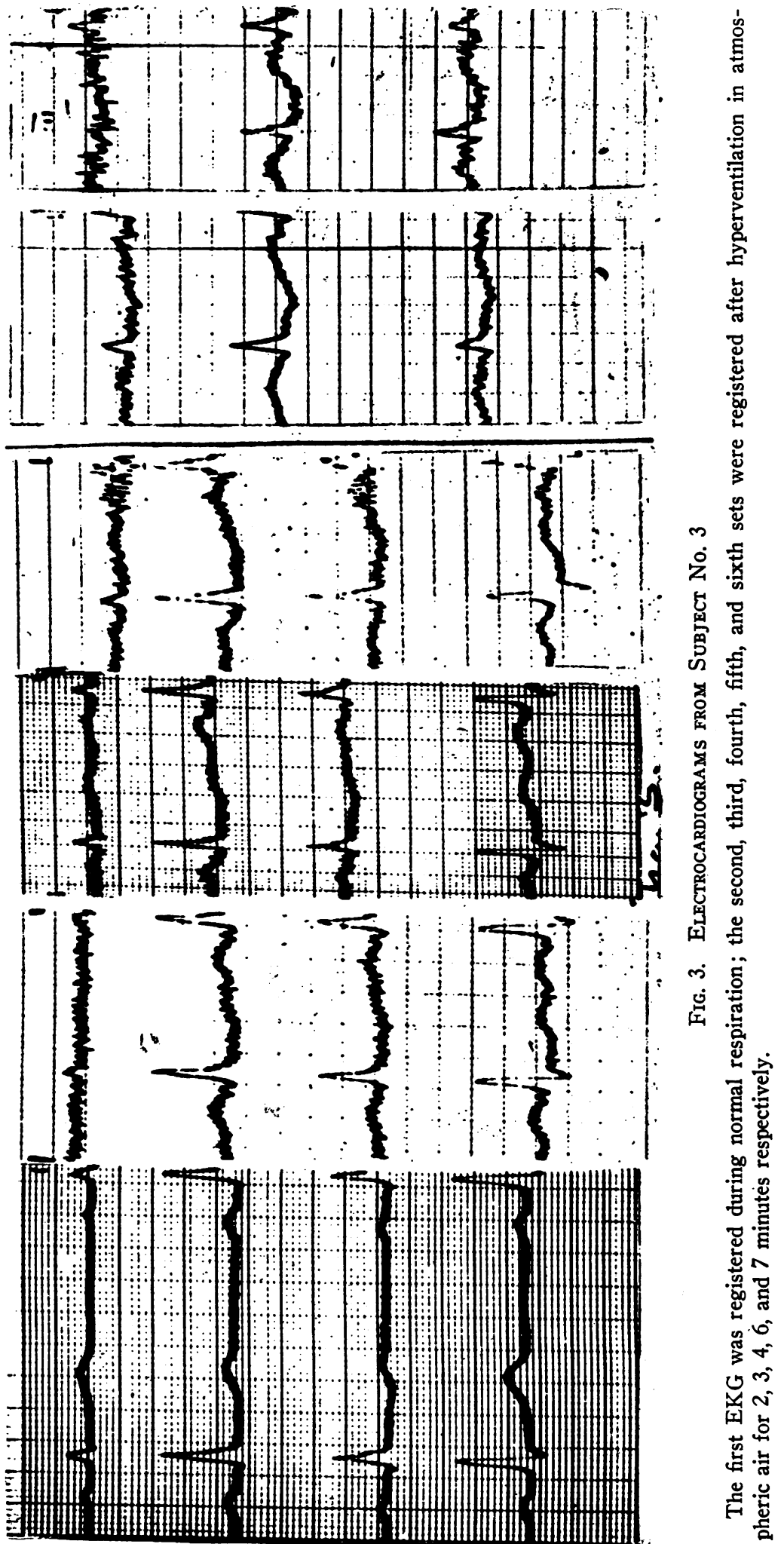


TABLE II

The electrocardiographic changes presented by subject no. 3 during voluntary hyperventilation Time indicated in seconds. Height of waves in $\mathrm{mm}$.

\begin{tabular}{|c|c|c|c|c|c|c|c|c|c|c|c|c|c|c|c|c|c|c|c|}
\hline Point of time & Rate & $\mathbf{P}-\mathbf{Q}$ & Q-T & $\mathbf{P}_{\mathbf{1}}$ & $\mathbf{P}_{2}$ & $\mathbf{P}_{8}$ & $P_{\mathbf{A R}}$ & $\mathbf{R}_{\mathbf{1}}$ & $\mathbf{R}_{\mathbf{2}}$ & $\mathbf{R}_{\mathbf{s}}$ & $\mathbf{R}_{\mathbf{R}}$ & S- $T_{1}$ & $S-T_{2}$ & S-T: & $S-T_{\mathbb{R}}$ & $T_{1}$ & $T_{2}$ & $T_{2}$ & $T_{\mathbb{R}}$ \\
\hline $\begin{array}{l}\text { Before hyperventilation } \\
\text { a. } 2 \mathrm{~min} \text {. of hyperventilation } \\
\text { a. } 3 \mathrm{~min} \text {. of hyperventilation } \\
\text { a. } 4 \mathrm{~min} \text {. of hyperventilation } \\
\text { a. } 6 \mathrm{~min} \text {. of hyperventilation } \\
\text { a. } 7 \mathrm{~min} \text {. of hyperventilation }\end{array}$ & $\begin{array}{r}72 \\
125 \\
120 \\
150 \\
130 \\
166\end{array}$ & $\begin{array}{l}0.32 \\
0.14 \\
0.14 \\
0.14 \\
0.14 \\
0.14\end{array}$ & $\begin{array}{l}0.37 \\
0.28 \\
0.30 \\
0.28 \\
0.28 \\
0.22\end{array}$ & $\begin{array}{l}1 \\
1 \\
1 \\
1 \\
1 \\
1 \\
1 \\
1\end{array}$ & 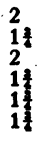 & $\begin{array}{l}1 \\
1 \\
1 \\
1 \\
1 \\
1\end{array}$ & $\begin{array}{l}1 \frac{1}{3} \\
1 \frac{1}{2} \\
1 \\
1 \frac{1}{2}\end{array}$ & $\begin{array}{l}3 \\
2 \\
3 \\
2 \\
3 \\
3\end{array}$ & $\begin{array}{r}12 \\
12 \\
10 \\
12 \\
8 \\
7\end{array}$ & $\begin{array}{r}8 \\
8 \\
6 \\
10 \\
4 \\
4\end{array}$ & $\begin{array}{r}11 \\
9 \\
8 \\
8\end{array}$ & $\begin{array}{r}\mathbf{0} \\
\mathbf{0} \\
\mathbf{0} \\
\mathbf{0} \\
+\mathbf{1} \\
? \mathbf{?}\end{array}$ & $\begin{array}{l}0 \\
-1 \\
-1 \frac{1}{2} \\
-2 \\
-2 \\
-1\end{array}$ & $\begin{array}{r}0 \\
-1 \\
-1 \\
-1 \\
-1 \\
-1\end{array}$ & $\begin{array}{c}0 \\
-1 \\
-1 \frac{1}{2} \\
-2\end{array}$ & $\begin{array}{r}1 \frac{1}{2} \\
0 \\
1 \\
1 \\
-1 \\
?\end{array}$ & $\begin{array}{r}2 \\
0 \\
0 \\
0 \\
-2 \\
-2\end{array}$ & $\begin{array}{r}* \\
0 \\
0 \\
0 \\
-1 \\
-1\end{array}$ & $\begin{array}{l}4 \\
1 \frac{1}{1} \\
1 \\
1\end{array}$ \\
\hline
\end{tabular}

* Diphasic.

man aged 30 (Figure 4). The first set of electrocardiograms was registered before the hyperventilation was commenced; and the following 3, after hyperventilation for 3,4 , and 6 minutes respectively. This experiment likewise revealed pronounced changes of S-T segment and $T$ waves in all 3 leads. The sizes of the individual changes appear from Table III.

The electrocardiographic examinations during voluntary hyperventilation in atmospheric air have shown that the following changes occur:

(1) sinus tachycardia

(2) a slight reduction of the time of conduction

(3) a shortening of the electric systole duration, so that the latter falls within the range of the normal values indicated by $\mathrm{Kaj} H$. Larsen (7)

(4) no indisputable change of the heights of the $P$ waves

(5) uncharacteristic changes of the heights of the $R$ waves

(6) depression of the S-T segment of at least 3 $\mathrm{mm}$. or more in 2 or more leads

(7) iso-electric, diphasic, or inverted $\mathrm{T}$ waves in 2 or more leads.

These electrocardiographic changes are highly indicative of a coronary insufficiency, since the criteria required by Levy, Williams, Bruenn, and Carr (8) are represented to the full, viz.,
(1) A total depression of the S-T segment in the 3 extremital leads and $4 \mathrm{~F}$ of no less than 3 mm., or

(2) depression of $\mathrm{S}-\mathrm{T}_{1}$ of at least $1 \mathrm{~mm}$. together with total or partial inversion of $T_{1}$, or

(3) a negative $T_{4 F}$ with no other changes, or

(4) iso-electric or diphasic $T_{4 F}$ as well as depression of $\mathrm{S}-\mathrm{T}_{4 \mathrm{~F}}$ of at least $1 \mathrm{~mm}$.

The spontaneous decrease in the electrocardiographic changes after the discontinuation of the hyperventilation was studied for all 4 experimental subjects. These examinations showed that the electrocardiogram becomes fairly normal after 5 minutes and is perfectly normal again after 10 minutes.

The electrocardiographic changes during continued hyperventilation in pure oxygen were likewise studied for all 4 women. In one case only did the electrocardiographic changes disappear after 6 minutes of hyperventilation in pure oxygen. In the other cases there was observed no decrease in the electrocardiographic changes.

The electrocardiographic changes during continued hyperventilation in a mixture of 5 per cent carbon dioxide, 20 per cent oxygen, and 75 per cent nitrogen. All the changes proved to disappear in the course of between 30 and 60 seconds in the cases of all 4 women.

The electrocardiographic changes during voluntary hyperventilation immediately after adminis-

TABLE III

The electrocardiographic changes presented by subject no. 4 during voluntary hyperventilation Time indicated in seconds. Height of waves in $\mathrm{mm}$.

\begin{tabular}{|c|c|c|c|c|c|c|c|c|c|c|c|c|c|c|c|}
\hline Point of time & Rate & $\mathbf{P}-\mathbf{Q}$ & Q-T & $\mathbf{P}_{\mathbf{1}}$ & $\mathbf{P}_{\mathbf{2}}$ & $\mathbf{P}_{\mathbf{z}}$ & $\mathbf{R}_{\mathbf{1}}$ & $\mathbf{R}$ & $R_{s}$ & $S-T_{1}$ & S-T $T_{2}$ & S-T $T_{2}$ & $T_{1}$ & $T_{2}$ & $T_{3}$ \\
\hline $\begin{array}{l}\text { Before hyperventilation } \\
\text { a. } 3 \mathrm{~min} \text {. of hyperventilation } \\
\text { a. } 4 \mathrm{~min} \text {. of hyperventilation } \\
\text { a. } 6 \mathrm{~min} \text {. of hyperventilation }\end{array}$ & $\begin{array}{r}90 \\
107 \\
143 \\
131\end{array}$ & $\begin{array}{l}0.14 \\
0.14 \\
0.13 \\
0.12\end{array}$ & $\begin{array}{l}0.32 \\
0.30 \\
0.26 \\
0.30\end{array}$ & $\begin{array}{l}1 \downarrow \\
1 \\
1 \\
1\end{array}$ & $\begin{array}{l}2 \frac{1}{2} \\
2 \frac{1}{2} \\
2 \frac{1}{2} \\
2 \frac{1}{2}\end{array}$ & $\begin{array}{l}1 \\
1 \\
1 \frac{1}{2} \\
1 \frac{1}{2}\end{array}$ & $\begin{array}{r}12 \\
9 \\
6 \\
7\end{array}$ & $\begin{array}{l}14 \\
14 \\
13 \\
15\end{array}$ & $\begin{array}{l}2 \\
6 \\
7 \\
8\end{array}$ & $\begin{array}{r}0 \\
-1 \\
-1 \\
-1\end{array}$ & $\begin{array}{r}0 \\
-2 \\
-1 \\
-2 \frac{1}{2}\end{array}$ & $\begin{array}{r}0 \\
-1 \\
0 \\
-2\end{array}$ & $\begin{array}{l}3 \frac{1}{2} \\
2 \\
1 \\
1\end{array}$ & $\begin{array}{l}2 \frac{1}{2} \\
1 \\
0 \\
0\end{array}$ & $\begin{array}{r}-1 \\
-1 \\
-1 \\
0\end{array}$ \\
\hline
\end{tabular}



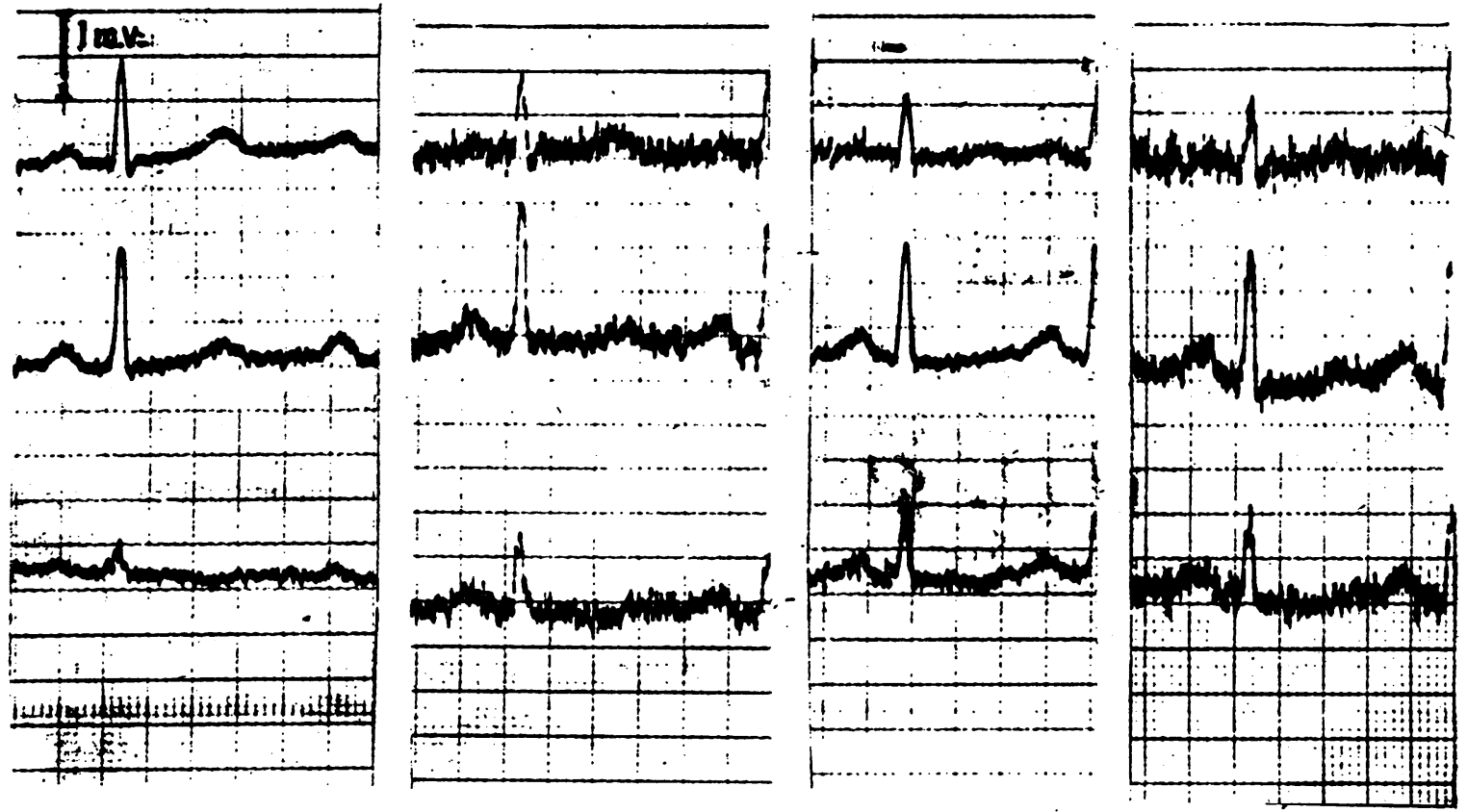

Fig. 4. Electrocardiograms from Subject No. 4

The first EKG was registered dưring normal respiration; the second, third, and fourth sets were registered after hyperventilation for 3,4 and 6 minutes respectively.

tration of $2 \mathrm{mgm}$. nitroglycerin. Double experiments with 2 of the women showed that administration of $2 \mathrm{mgm}$. nitroglycerin has no influence on the occurrence of the electrocardiographic changes.

\section{DISCUSSION}

The experiments mentioned in this paper show that distinct electrocardiographic changes indicative of coronary insufficiency will occur in normal man during voluntary hyperventilation in atmospheric air. But there is seen no prolongation of the electric systole duration; nor should we expect to find such a prolongation after Schultzer and Lebel's (9) demonstration of the fact that the concentration of calcium ions does not decrease during attacks of hyperventilation tetany.

It has been maintained ( 3 ) that the transitory changes in the electrocardiogram may be due to a change of position of the heart caused by a local tetany of the diaphragm. It is, however, not very likely that a change of position would be able to bring about the changes mentioned here, which apply particularly to $\mathrm{S}-\mathrm{T}$ segment and $\mathrm{T}$ waves; nor is it possible by registration of electrocardiograms at the stage of deepest inspiration to demonstrate changes that on any point resemble those described here. It is therefore to be supposed that the changes are due to a reduction in the supply of oxygen to the myocardium. This must be taken as a sign that the precordial sensations appearing during hyperventilation in atmospheric air are of myocardial origin.

A transitory reduction in the supply of oxygen to the myocardium must have been caused by changes in the factors conditioning the liberation of oxygen during the flowing of the blood through the capillaries, either on account of changed circumstances of dissociation for the oxyhemoglobin, or on account of changed conditions of flowing.

Bohr, Hasselbalch, and Krogh (10) have proved that the dissociation of the oxyhemoglobin is impeded by a reduction of the carbon dioxide tension in the blood. This phenomenon has been studied further by Barcroft and collaborators (11), who plotted the curves illustrated in Figure 5.

Figure 5 shows the dissociation curves of the oxyhemoglobin at different carbon dioxide tensions. The figures below the abscissa axis indicate the oxygen tension in $\mathrm{mm}$. $\mathrm{Hg}$, while the ordinate indicates the percentage of oxyhemoglobin; 
and the figures above the individual curves indicate the respective carbon dioxide tensions. Under normal conditions, the oxygen tension is 100 $\mathrm{mm}$., and the carbon dioxide is $40 \mathrm{~mm}$. in arterial blood, approximately. In venous blood, the corresponding tensions are 40 and $45 \mathrm{~mm}$. respectively. The oxyhemoglobin will thus, under normal conditions, give off about 5 volumes per cent of oxygen during the flow of the blood through the capillaries. During hyperventilation, carbon dioxide tension can easily be reduced to $20 \mathrm{~mm}$., while at the same time the oxygen tension remains unchanged. There occurs no rise in the carbon dioxide tension in the venous blood, because there is found an excess of fixed cations to bind the produced carbon dioxide, and the fall of the oxygen tension does not exceed the normal. It follows from this that the liberation of oxygen is impeded rather considerably under such conditions. It appears from Figure 5 that, at a carbon dioxide tension of about $20 \mathrm{~mm}$. $\mathrm{Hg}$, the blood gives off only 2.5 volumes per cent of oxygen during its flow through the capillaries. At respiration in atmospheric air the physically bound amount of oxygen in the blood is so small ( 0.20 volume per cent), that it is of no significance. But if the per-

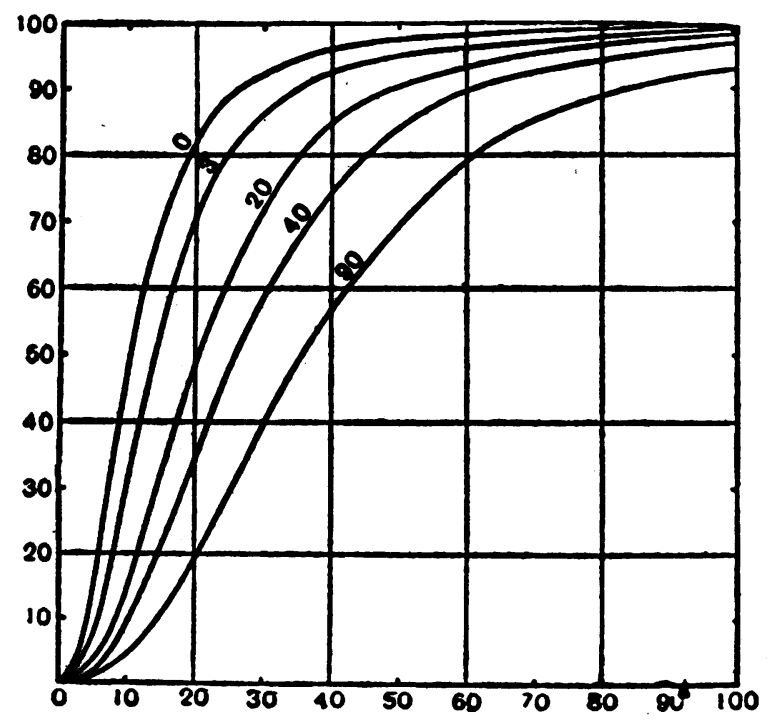

Fig. 5. Dissociation Curves of Oxyhemoglobin at Different Carbon Dioxide Tensions

The abscissa indicates the oxygen tension in $\mathrm{mm} . \mathrm{Hg}$; and the ordinate, the percentage of oxyhemoglobin; the figures above the individual curves indicate the respective carbon dioxide tensions. son experimented on breathes in pure oxygen, the physically bound oxygen will increase to a rather considerable amount. Under such conditions, the oxygen tension in the arterial blood rises to nearly $700 \mathrm{~mm} . \mathrm{Hg}$, whereas, on account of the great fall of tension in the tissues, it is normal $(40 \mathrm{~mm}$.) in the venous blood. At the above tensions the arterial blood contains approximately 1.75 volumes per cent, and the venous blood, approximately 0.10 volume per cent of physically bound oxygen, which gives an extra oxygen liberation in the capillaries of about 1.65 volumes per cent. This figure added to the previously mentioned 2.5 volumes per cent, which is liberated from the oxyhemoglobin, gives 4.15 volumes per cent, a figure so high that this amount should be able to make the signs of myocardial hypoxemia subside, if the latter had been brought about exclusively by the phenomena mentioned above. Our experiments with continued respiration in pure oxygen show, however, that the signs of hypoxemia could be removed in one case only, and even in that case not till after 6 minutes had elapsed. This must be regarded as a proof that other factors must play a greater part than the changed dissociation of oxyhemoglobin.

In all the experiments of continued respiration in a mixture of 5 per cent carbon dioxide, 20 per cent oxygen, and 75 per cent nitrogen, the electrocardiographic signs of myocardial hypoxemia disappeared within less than a minute. This seems indicative that the transitory coronary insufficiency is due to the acapnia and the alkalosis, and that the changed hemodynamic conditions caused by the hyperventilation itself play no part.

The tachycardia caused by the hyperventilation can have no influence on the occurrence of the electrocardiographic changes, since no such changes are seen during hyperventilation in air rich in carbon dioxide, although a pronounced tachycardia is present also in these experiments.

The arterial blood pressure undergoes no changes during the hyperventilation (12), so accordingly the demonstrated myocardial hypoxemia must have been caused either by changes in the state of constriction of the coronary vessels, or by an increased intramyocardial pressure resulting in inhibited flowing of blood, or finally by a combination of these factors.

It has been shown, through numerous animal experiments (13 to 18 ), that a reduced carbon 
dioxide tension, or an otherwise produced shift of the reaction of the passing fluid towards the basic side, brings about a pronounced constriction of the coronary vessels. Thus a shift of the $\mathrm{pH}$ from 7.35 to 7.70 will reduce the coronary flow by approximately 50 per cent. Yandell Henderson (19) has proved, in convincing experiments on dogs, that the volume of the heart decreases remarkably during hyperventilation in such a way that the diastolic volume is reduced first and then the systolic volume, after which the heart finally stops in the systole. As administration of large doses of nitroglycerin immediately before the beginning of the hyperventilation has no influence on the occurrence of the electrocardiographic changes, it seems reasonable to conclude that constrictions of the coronary vessels can be of no essential importance for the appearance of the myocardial hypoxemia during hyperventilation. Accordingly, there is reason to presume that the transitory myocardial hypoxemia developed during hyperventilation is conditioned in the first instance on a reduced flowing of blood through the coronary vessels on account of a compression of the latter, due to an increased intramyocardial tension.

The facts demonstrated through these experiments are of rather considerable practical importance in various cases. Thus, for instance, there have been demonstrated light, transitory, electrocardiographic changes in the febrile periods of nearly all febrile, infectious diseases. These changes have been taken as signs of a transitory, toxic affection of the myocardium, an explanation which is probably correct in some cases; but on the other hand it should be borne in mind that febrile patients present a rather pronounced hyperventilation, even more pronounced than what corresponds to the increase in the metabolic rate. Considering that even a slight hyperventilation can bring about small changes in the electrocardiogram, we cannot leave out of account the possibility that a contingent hypervientilation may have a share in the above changes.

Finally, also, the electrocardiographic, functional tests and the conclusions drawn from them should be discussed in brief. In electrocardiographic examinations after muscular work, or during respiration of a mixture of air poor in oxygen, it is generally presumed that an electrocardiographically demonstrated coronary insufficiency, according to Levy's criteria, is an unquestionable sign of a possible latent coronary sclerosis. This can, however, hardly be sanctioned as a general rule available to all cases, for it is a well-known fact that untrained individuals hyperventilate during muscular work, so that accordingly there should be a possibility that electrocardiographic changes, if present, might have been brought about by acapnia. This fact must play a rather considerable part in the cases in which the differential diagnosis stands between coronary affection and the effort syndrome, as the author has previously pointed out (20) that patients suffering from the effort syndrome hyperventilate so much during muscular work that there occurs a pronounced vasoconstriction of the big extremital arteries. Distinct electrocardiographic changes have in some cases been observed (21) in apparently healthy young people at the ordinary hypoxemia tests, where the subject is made to breathe in a mixture of air consisting of 10 per cent oxygen and 90 per cent nitrogen. This can easily be explained as having its cause in the involuntary hyperventilation, which occurs in all individuals who breathe in air that is poor in oxygen.

The facts just reported argue, in my opinion, in favor of using the hypoxemia test, and not the working electrocardiogram, for the diagnosis of latent coronary affections, and of using for the hypoxemia test a mixture of air which contains 2 or 3 per cent carbon dioxide in order to counteract the acapnia brought about by the hyperventilation.

\section{SUM MARY}

1. Voluntary hyperventilation, which removes carbon dioxide, brings about distinct electrocardiographic signs of myocardial hypoxemia in normal human beings. These signs disappear again in the course of about 10 minutes after the discontinuation of the hyperventilation.

2. Continued hyperventilation in pure oxygen brings about no definite decrease in the electrocardiographic changes. This means that apparently the changes are not due exclusively to the dissociation of the oxyhemoglobin, having been impeded by the reduced carbon dioxide tension.

3. Continued hyperventilation in a mixture of 5 per cent carbon dioxide, 20 per cent oxygen, and 75 per cent nitrogen makes the electrocardio- 
graphic changes disappear within less than a minute. Consequently, it is to be supposed that the changes are due to the acapnia and the alkalosis. Numerous animal experiments have been carried out, on the basis of which it seems justifiable to conclude that the myocardial hypoxemia is brought about either by a constriction of the coronary vessels, or by an increased intramyocardial tension, or by a combination of these 2 factors.

4. Administration of large doses of nitroglycerin immediately before the commencement of the experiment does not prevent the occurrence of the electrocardiographic changes. This goes to show that such changes cannot be caused by a coronary constriction alone, but must be due chiefly to an increase in the intramyocardial tension.

5. Finally, it is pointed out that the facts demonstrated through these experiments may be of rather considerable practical importance at the estimation of electrocardiograms registered after bodily exertion or during respiration of air deficient in oxygen, since an involuntary hyperventilation brought about by these procedures may result in electrocardiographic changes in normal human beings.

\section{CONCLUSIONS}

Voluntary hyperventilation, which removes carbon dioxide, brings about distinct electrocardiographic signs of myocardial hypoxemia in normal human beings.

The myocardial hypoxemia demonstrated electrocardiographically is probably due. to the increased intramyocardial tension caused by the acapnia and the alkalosis. At the estimation of electrocardiograms registered after bodily exertion or during respiration of oxygen-deficient or carbon dioxide-free air, one should bear in mind the fact that these procedures will in many cases bring about an involuntary hyperventilation, which may cause electrocardiographic changes to occur.

Addendum. On account of the difficult conditions of communication during the war, I did not learn about William Paul. Thompson's investigations from 1943 (22) till after the conclusion of the work here presented. Thompson has demonstrated electrocardiographic changes of a kind similar to those described here in patients with the hyperventilation syndrome, and in normal persons during hyperventilation. $\mathrm{He}$ is of the opinion that such changes are due to the alkalosis. No detailed description is given, however, of the mechanism of the occurrence of these changes.

\section{BIBLIOGRAPHY}

1. Kronenberger, F., and Ruffin, H., Herzstramkurve und vegetatives Nervensystem mit besonderer Berücksichtigung der Hyperventilationstetanie. Deutsches Arch. f. klin. Med., 1929, 165, 257.

2. McCance, R. A., Spontaneous overbreathing tetany. Quart. J. Med., 1932, 1, 247.

3. Lemi, Guido, L'elettro-cardiogramma dopo iperventilazione. Riforma med., 1935, 51, 663.

4. Berker, P. S., Shrader, E. L., and Ronzoni, E., The effects of alkalosis and acidosis upon the human electrocardiogram. Am. Heart J., 1939, 17, 169.

5. Barach, A. L., and Steiner, A., Effect of inhalation of high oxygen concentrations, with and without carbon dioxide, on the electrocardiogram. Proc. Soc. Exper. Biol. and Med., 1940, 45, 175.

6. Larsen, Kaj H., Om forandringer i elektrocardiogrammet hos sunde og syge under experimental iltmangel. Thesis, Copenhagen, 1938.

7. Larsen, K. H., and Skulason, T., Det normale elektrocardiogram. I. Nord. Med., 1941, 9, 350.

8. Levy, R. L., Williams, N. E., Bruenn, H. G., and Carr, H. A., The "Anoxemia test" in the diagnosis of coronary insufficiency. Am. Heart J., 1941, 21, 634.

9. Schultzer, P., and Lebel, H., Spontaneous hyperventilation tetany. Acta Ugesk. f. laeger, 1939, 101, 1312.

10. Bohr, Chr., Hesselbalch, K. A., and Krogh, A., Ueber einen in biologischer Beziehung wichtigen Einfluss, den die Kohlensäurespannung des Blutes auf dessen Sauerstoffbindung übt. Skand. Arch. Physiol., 1904, 16, 402.

11. Barcroft, J., and Means, J. H., The effect of $\mathrm{CO}_{2}$ on the dissociation curve of hemoglobin. J. Physiol., 1914, 47, XXVII.

12. Christensen, B. Chr., Studies on hyperventilation. I. Influence of the carbon dioxide tension in the arterial blood on the state of contraction of the large arteries in man. Acta Med. Scandinav., 1945, 120, 485 (a).

13. Barcroft, Joseph, and Dixon; W. E., The gaseous metabolism of the mammalian heart. J. Physiol., $1907,35,182$.

14. Markwalder, Josef, and Starling, E. H., A note on some factors which determine the blood flow through the coronary circulation. J. Physiol., 1913, 47, 275.

15. Ludkovich, Action of alkali and acids upon peripheral and coronary blood. Thesis. Petrograd, 1916, cit. Anrep, G. V., Physiol. Review, 1926, 6, 596.

16. Iwai, M., Untersuchungen über den Einfluss der Wasserstoffionenkonzentration auf die Coronargefässe und die Herztätigkeit. Arch. f. d. ges. Physiol., 1924, 202, 256. 
17. Hilton, R., and Eickholz, F., The influence of chemical factors on the coronary circulation. J. Physiol., 1925, 59, 413.

18. Anrep, G. V., and Stacey, R. S., Comparative effect of various drugs upon the coronary circulation. $\mathrm{J}$. Physiol., 1927, 64, 187.

19. Henderson, Yandell, Acapnia and shock. I. Am. J. Physiol., 1908, 21, 126.
20. Christensen, B. Chr., Studies on the effort syndrome. II. The conditions of the large arteries during muscular work, illustrated by oscillometric measurements. Acta Med. Scandinav., 1945, 121, 319 (b).

21. Nylin, G., Die Frühdiagnose der Koronarinsuffizienz. Cardiologia, 1944, 8, 263.

22. Thompson, W. P., Electrocardiogram in hyperventilation syndrome. Am. Heart J., 1943, 25, 372. 